\title{
Novel smart composite materials for industrial wastewater treatment and reuse
}

\author{
Joginder Singh Paneysar ${ }^{1} \cdot$ Sumeet Jain ${ }^{1} \cdot$ Nida Ahmed $^{2} \cdot$ Stephen Barton $^{2} \cdot$ Premlata Ambre $^{1} \cdot$ Evans Coutinho $^{1}$
}

Received: 30 January 2020 / Accepted: 15 April 2020 / Published online: 16 May 2020

(C) The Author(s) 2020 OPEN

\begin{abstract}
With the current levels of industrial development it is very difficult to prevent organic pollutants and toxic heavy metals from contaminating water. Thus purification of contaminated industrial water and its reuse is a global concern. The present study highlights application of a novel standalone technology in the form of polymers that efficiently extract a range of organic and inorganic impurities simultaneously for reuse of industrial effluent. Previous studies have focused on water soluble synthetic polymers for removal of organic contaminants, while biodegradable polymers are being used for extraction of toxic metals from water. Our earlier reports already describe a combination of synthetic and natural polymers with the ability to eliminate organic and inorganic spiked impurities from water on a lab scale. In the present work a series of novel smart composite materials have been synthesized and fully characterized. The avant-garde novelty of these materials for simultaneous removal of organic impurities such as phenols, anhydrides, textile dyes, pesticides, herbicides, antibiotics and inorganic heavy metals has been demonstrated and the novel polymers have shown a removal efficiency of more than $90 \%$ for each of the contaminants. Furthermore, the established 4-cycle reusability and an extensive reduction in levels of chemical oxygen demand suggests these materials would act as an improvement to the current methods for treating effluent water. The high reproducibility in synthesis, properties and elimination spectrum brands them as promising materials for industrial water remediation and reuse.
\end{abstract}

Keywords Pullulan · Industrial wastewater reuse $\cdot$ Smart composite materials · Adsorption isotherm · ICP-OES

\section{Introduction}

Good quality of water is a crucial parameter for the healthcare of society. With the continuous use of water for numerous industrial procedures, a balance needs to be established between its demand and supply. Due to its polarity and hydrogen bonding it has ability to dissolve or suspend many different contaminants. The contaminants from pharmaceutical, textile, chemical, agrochemical and various other industries may represent hazards in themselves or may be able to react with other substances, resulting in serious health complications [1]. Moreover with the imposition of various laws and zero liquid discharge (ZLD) for industrial effluent by regulatory agencies, water treatment has become a mandatory aspect for better conservation [2]. With the advancement of technology, various methods have been employed for effluent management including flocculation, electrolysis, electrodialysis, physical/biological adsorption, ion exchange, reverse osmosis and membrane separation [3]. The applicability of a specific method is exclusively dependent on the nature and the content of the effluent and yet none of these methods deliver on all the water quality parameters in their individual capacity. Hence, there is need for a

$\triangle$ Stephen Barton, s.barton@kingston.ac.uk| 'Department of Pharmaceutical Chemistry, Vasvik Research Wing, Bombay College of Pharmacy (Autonomous), Mumbai 400 098, India. ${ }^{2}$ School of Life Sciences, Pharmacy and Chemistry, Kingston University London, Kingston-upon-Thames KT1 2EE, UK. 
unique, safe, innovative and cost-effective technology that can be readily assimilated in the current industrial setup. Our earlier reports, describe the applicability of one such technology using smart biodegradable polymers that remove hazardous organic chemicals, metal ions and dyes from spiked water under the influence of temperature on a lab scale $[4,5]$. In continuation of the earlier proceedings, in this paper we present an innovative technology in the form of a novel series of temperature responsive biodegradable materials as composites that have ability to efficiently extract the dissolved metal ions and impurities present in pharmaceutical, chemical agrochemical and textile industrial effluents. The composite materials have been developed as a promising approach to encourage water reuse by industries through their direct assimilation into the current effluent treatment setup. The materials are fabricated with an aim to reduce the water stress caused by extensive use and pollution from various industrial activities which in turn is a prime factor that demands the need for efficient water reclamation.

The smart composite materials are made up of smart polymers. These polymers show a characteristic behavior with respect to the environmental conditions in which they are present. This behavior is characterized by a change in phase or change in physical properties. The triggering factor for such behavioral change in the polymer can be light, temperature, $\mathrm{pH}$, magnetic field or even enzymes [6]. Of the smart polymers, temperature responsive polymers change their phase with changes in surrounding temperature. Such polymers contain hydrophilic groups, which interact strongly with water molecules. Also, there is a prevalence of hydrophobic moieties in addition to the large number of hydrophilic groups. Therefore, they experience both repulsive and attractive forces with water molecules and the delicate balance of hydrophilic and hydrophobic moieties determines their water solubility. Upon heating, these polymers precipitate due to a change in the conformation of the chains at a specific temperature called the lower critical solution temperature (LCST). When temperature rises, the solubilized polymeric chains take up a coil structure. In order to reduce their free energy, the polymers start to aggregate and reduce their contact with water molecules. At or above the LCST a complete transformation is achieved that results in efficient aggregation and precipitation of the polymer. This precipitation is attributed to the domination of the hydrophobic groups [7]. These groups enable temperature responsive polymers to have a unique property of extracting organic impurities from aqueous solutions by adsorption [8]. Despite their wide applicability, temperature responsive polymers suffer the consequences of not being environment friendly. This is in contrast to biodegradable polymers that have been reported as chelating agents and thus adsorb inorganic water soluble impurities and dyes [9] from effluent but lack the shelf life for prolonged use. Therefore, a combination of both the polymers as a graft not only extracts organic and inorganic impurities simultaneously but also imbibes biodegradability to the overall polymer [4]. Hence, the current paper demonstrates co-polymerization or grafting of a temperature responsive synthetic polymer onto a biodegradable polymer to generate novel smart composite materials for exclusive extraction of phenols, anhydrides, textile dyes, pesticides, herbicides, antibiotics and inorganic heavy metals simultaneously from water.

\section{Materials and methods}

The natural polymer pullulan (Mol wt. 200,000 Da.) was a gift sample from Nagase India Pvt. Ltd. (Mumbai, India). The monomer $\mathrm{N}$-isopropylacrylamide (NIPAAM) was a gift sample from SLN Pharma Chem (Mumbai, India), and dimethylaminoethyl methacrylate (DMAEMA) was a gift sample from Alfa Aesar (Mumbai, India), Diethylacrylamide (DEA) and N-vinylcaprolactam (NVCL) were procured from $\mathrm{TCl}$ chemicals (Chennai, India). The free radical initiator ceric ammonium nitrate (CAN) was purchased from S. D. Fine Chemicals (Mumbai, India) and dialysis membrane (12,000-14,000 Da,) from Hi-media (Mumbai, India).

\section{Methods}

\subsection{Synthesis of functionalized smart composite materials}

The composite materials were synthesized as reported by Ghimici et al. [10]. with modifications. In this pullulan, $1.0 \mathrm{~g}$ $(0.005 \mathrm{mmol})$ was dissolved in $12 \mathrm{ml}$ of $0.01 \mathrm{M}$ nitric acid solution in a two-necked flask equipped with a nitrogeninlet and a rubber septum. The flask was immersed in a thermostated water bath maintained at $25^{\circ} \mathrm{C}$. The solution was purged with nitrogen for $30 \mathrm{~min}$ and a nitrogen atmosphere was maintained throughout the polymerization process. CAN, $0.88 \mathrm{~g}(1.6 \mathrm{mmol})$ solubilized in $4 \mathrm{ml}$ $0.01 \mathrm{M}$ nitric acid solution was added. The solution was stirred for $10 \mathrm{~min}$ to induce free radicals on the pullulan chains. This was followed by addition of $1.13 \mathrm{~g}$ NIPAAM $(10 \mathrm{mmol})$, and the reaction was continued for $20 \mathrm{~h}$ at $25^{\circ} \mathrm{C}$. The reaction was terminated by addition of $1 \mathrm{~N}$ aqueous $\mathrm{NaOH}$ solution till alkaline. The reaction mixture was poured into methanol, filtered, washed and extracted again with methanol for $24 \mathrm{~h}$ in order to remove polymerized NIPAAM homopolymer. The product was then warmed to $50{ }^{\circ} \mathrm{C}$ to precipitate the graft polymer which was dialyzed for 4 days and then lyophilized. Table 1 gives 
Table 1 Smart composite grafts of pullulan (Pullulan-1 g, $0.01 \mathrm{mmol})$

\begin{tabular}{|c|c|c|}
\hline Code & Smart composite material & Monomer quantity $(A)$ \\
\hline GP-09 & Pullulan- $\mathrm{g}$-N-isopropylacrylamide & $\begin{array}{l}\text { N-Isopropylacrylamide } \\
(1.13 \mathrm{~g}, 10 \mathrm{mmol})\end{array}$ \\
\hline GP-10 & Pullulan- $g-\mathrm{N}, \mathrm{N}$-diethylacrylamide & $\begin{array}{l}\text { N,N-Diethylacrylamide } \\
(1.27 \mathrm{~g}, 10 \mathrm{mmol})\end{array}$ \\
\hline GP-11 & $\begin{array}{l}\text { Pullulan- } g-2-(\mathrm{N}, \mathrm{N}-\text { dimethylamino) } \\
\text { ethylmethacrylate }\end{array}$ & $\begin{array}{l}\text { 2-(N,N-Dimethylamino) } \\
\text { ethylmethacrylate } \\
(1.57 \mathrm{~g}, 10 \mathrm{mmol})\end{array}$ \\
\hline GP-12 & Pullulan-g-N-vinylcaprolactum & $\begin{array}{l}\text { N-Vinylcaprolactum } \\
(1.39 \mathrm{~g}, 10 \mathrm{mmol})\end{array}$ \\
\hline
\end{tabular}

the details of the quantities of other monomers used and the graft polymers synthesized (Fig. 1).

\subsection{Determination of LCST of the material under the influence of temperature}

LCST was determined by the cloud point method wherein the temperature of a $2.5 \%$ solution of material was linearly increased from 20 to $50^{\circ} \mathrm{C}\left(1{ }^{\circ} \mathrm{C} / \mathrm{min}\right)$. The temperature at which the solution turned turbid was noted as the LCST. The LCST was confirmed using a Mettler (Toledo) DSC 822e unit.

\subsection{FT-IR}

Potassium bromide $(\mathrm{KBr})$ discs with the copolymers were prepared using an electrically operated Techno Search Instruments $\mathrm{KBr}$ press model HP-15 (Mumbai, India). IR spectra were recorded on a Jasco FTIR-5300 Fourier transform spectrophotometer with a resolution of $4 \mathrm{~cm}^{-1}$.

\section{$3.4{ }^{1} \mathrm{H}-\mathrm{NMR}$}

NMR spectra of the copolymers were recorded using a Brüker Avance III $800 \mathrm{MHz}$ FT-NMR spectrometer. The NMR samples were made in solution comprising $0.9 \mathrm{ml} \mathrm{H}_{2} \mathrm{O}$ and $0.1 \mathrm{ml} \mathrm{D}_{2} \mathrm{O}$ mixture.

Fig. 1 General scheme for graft reaction

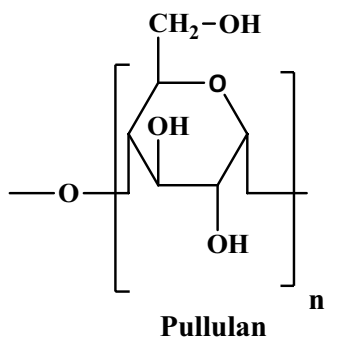

\subsection{Molecular weight determination}

\subsubsection{Extraction of temperature responsive polymers from the composite material [10]}

To determine the amount of temperature responsive polymers grafted onto pullulan backbone, the smart composite materials were subjected to hydrolysis using $70 \% \mathrm{v} / \mathrm{v}$ solution of sulphuric acid at room temperature for $9 \mathrm{~h}$. This resulted in separation of pNIPAAM/pDMAEMA/ $\mathrm{pDEA} / \mathrm{pNVCL}$ chains from the respective materials which were extracted using methanol followed by their precipitation in solution using diethyl ether to obtain the homopolymers.

The molecular weights of homopolymers were then determined from viscosity measurements using the Mark-Houwink equation given below,

$[\eta]=K M^{a}$

[n] - Intrinsic viscosity, K \& a-Specific set of constants obtained from literature and $\mathrm{M}-$ Molecular weight of the homopolymer.

Further, the molecular weights of the final smart composite materials were determined using the following equation [4],

$G R=\frac{\left(W_{g}-W_{p}\right) / M W_{\text {homo }}}{W_{p} / M W_{p}}$

$M W_{g}=M W_{p}+M W_{\text {homo }} \times G R$

$\mathrm{GR}$ - grafting ratio, $\mathrm{W}_{\mathrm{g}}$ - final weight of grafted polymer, $\mathrm{W}_{\mathrm{p}}$-weight of pullulan, $\mathrm{MW}_{\text {homo }}$ - molecular weight of homopolymer, $\mathrm{MW}_{\mathrm{p}}$-molecular weight of pullulan, $\mathrm{MW}_{\mathrm{g}}$ - molecular weight of graft polymer.

\subsection{Surface area determination}

Brunauer-Emmett-Teller (BET) surface area analysis and Barrett-Joyner-Halenda (BJH) pore size and volume analysis were performed on a Belsorp Mini II (Metrohm, India).

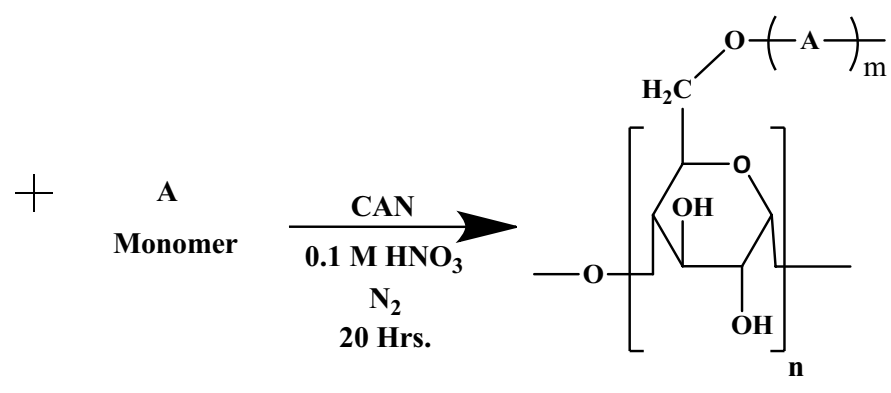

SN Applied Sciences A SPRINGER NATURE journa 
Nitrogen adsorption and desorption by the polymer were studied. The minimum measurement of the instrument for surface area was $0.01 \mathrm{~m}^{2} / \mathrm{g}$ and range for pore size was 0.35 to $200 \mathrm{~nm}$. A weighed sample of the GPA was loaded into a glass tube and, as pre-treatment, was degassed for $3 \mathrm{~h}$ at $110^{\circ} \mathrm{C}$ and $10^{-2} \mathrm{kPa}$ pressure. The sample was then weighed and loaded into the instrument for analysis.

\subsection{Evaluation and optimization of adsorption potential}

The novel smart composite materials were made with an aim to adsorb and extract various organic as well as inorganic impurities from water. Since the range of impurities is complex, it was found necessary to adapt various techniques like UV-visible spectrometry (Jasco V-630), HPLC (Jasco PU-2080 binary pump system), Inductively Coupled Plasma-Optical Emission Spectroscopy (ICP-OES) [Teledyne Leeman labs Prodigy7] and titrimetric to evaluate the proportional removal (\%) of various impurities from water. Reduction in levels of Chemical Oxygen Demand (COD) was an attempt to gauge the applicability of the smart composite materials for treatment of industrial effluents. Table 2 describes the methods developed and used for specific impurities.

A fixed concentration of each impurity with absorbance in the linear range of the Beer-Lambert law was selected, and the solution was treated with the smart composite material by heating above the respective LCST. The solution was then filtered and the precipitate removed followed by measurement of absorbance for the filtrate solution. The proportional removal was calculated using Eq. (4):

Proportional impurity removal $(\%)=\frac{C_{o}-C_{e}}{C_{o}} \times 100$

where $C_{0}$ : impurity concentration before treatment, and $\mathrm{C}_{\mathrm{e}}$ : impurity concentration after equilibrium treatment. The proportional impurity removal for ICP-OES was determined by comparing the reduction in concentrations of metal ions before and after treatment. All studies were carried out in triplicate.

\subsubsection{COD analysis of samples [11]}

The chemical oxygen demand is a direct measure of the load of dissolved organic substances and impurities present in effluents. The standard COD titration method was used for determination of dissolved organic load of the effluent samples and was calculated by the following equation,

Table 2 Analytical methods used for evaluation of adsorption potential for various impurities

\begin{tabular}{|c|c|c|c|}
\hline S. no & Class of Impurity & Impurity & Method \\
\hline \multirow[t]{2}{*}{1.} & \multirow[t]{2}{*}{ Organic } & Chlorophenol & $\mathrm{HPLC}$ at $266 \mathrm{~nm}$ \\
\hline & & Phthalic anhydride & UV at $273 \mathrm{~nm}$ \\
\hline 2. & Inorganic & $\begin{array}{l}\text { Arsenic, mercury, chromium, iron, lead, copper, cadmium, } \\
\text { cobalt, zinc, manganese, magnesium, antimony and sele- } \\
\text { nium }\end{array}$ & ICP-OES \\
\hline \multirow[t]{5}{*}{3.} & \multirow{2}{*}{$\begin{array}{l}\text { Textile dyes } \\
\text { a. Basic }\end{array}$} & Methylene blue & UV at $650 \mathrm{~nm}$ \\
\hline & & Crystal violet & UV at $583 \mathrm{~nm}$ \\
\hline & \multirow[t]{3}{*}{ b. Acidic } & Methyl orange & UV at $465 \mathrm{~nm}$ \\
\hline & & Indigo carmine & UV at $610 \mathrm{~nm}$ \\
\hline & & Congo red & UV at $498 \mathrm{~nm}$ \\
\hline \multirow[t]{3}{*}{4.} & \multirow[t]{3}{*}{ Agrochemicals } & Cypermethrin (insecticide) & UV at $220 \mathrm{~nm}$ \\
\hline & & Chlorpyrifos (pesticide) & UV at $224 \mathrm{~nm}$ \\
\hline & & 2,4-Dichlorophenoxyacetic acid (Herbicide) & UV at $235 \mathrm{~nm}$ \\
\hline \multirow[t]{3}{*}{5.} & \multirow[t]{3}{*}{ Pharmaceuticals } & Ciprofloxacin & UV at $275 \mathrm{~nm}$ \\
\hline & & Ofloxacin & UV at $296 \mathrm{~nm}$ \\
\hline & & Isoniazid & UV at $263 \mathrm{~nm}$ \\
\hline 6. & Effluent water (CETP) & $\begin{array}{l}\text { Mixture of effluent from chemical, dyeing and pharmaceuti- } \\
\text { cal industries }\end{array}$ & $\begin{array}{l}\text { Chemical Oxygen Demand (COD) by } \\
\text { titration }\end{array}$ \\
\hline 7. & Industrial effluent water & Fungicides, chemicals, organic matter & COD reduction by titration \\
\hline
\end{tabular}

SN Applied Sciences 
$\operatorname{COD}(\mathrm{ppm})=\frac{(\text { Blank }- \text { sample }) \times \text { Normality of Ferrous ammonium sulphate } \times \text { mol. wt. of oxygen } \times 1000}{\text { Volume of sample }(\mathrm{ml})}$

A 500 ppm solution of potassium hydrogen phthalate (KHP) was used as the standard for calibration and standardization of the titrimetric method.

\subsection{Optimization of adsorption conditions [5]}

The smart composite materials are highly soluble in water and precipitate only above the LCST. Precipitation is caused by transformation of the material into hydrophobic coiled chains that are responsible for adsorption of the impurities. To determine the materials maximum adsorption ability, initially a low concentration ( $1 \mathrm{mg} /$ $\mathrm{ml})(0.1 \%)$ of material was added to a solution containing a known concentration of impurity. The solution temperature was gradually increased and then kept constant above the LCST of individual materials for a range of times (contact time optimization).

Similarly, proportional removal was also determined for $0.2 \%$ and $0.4 \% \mathrm{w} / \mathrm{v}$ concentration of materials as to determine the maximum impurity adsorption.

\subsection{Adsorption isotherm determination [5]}

Adsorption isotherm experiments were carried out to determine and explain the relationship between Ceq, the equilibrium concentration of the adsorbate (materials) and $\mathrm{q}_{\mathrm{e}}$, the amount adsorbed on the surface. The Langmuir and Freundlich isotherm models were used to analyse the materials above their LCST at the optimised temperature and contact times as determined above.

\subsubsection{Langmuir adsorption isotherm}

The Langmuir model exhibits a linear relationship for the amount adsorbed per unit mass of adsorbent material. It is distinguished by three factors-adsorption, desorption and kinetic rates-combined with the total number of free sites available on the surface. The collective surface concentration of impurity is denoted by q. Equation (6) is the linear form of the Langmuir equation:

$\frac{C_{e}}{q_{e}}=\frac{1}{q_{m} K_{L}}+\frac{C_{e}}{q_{m}}$

where $q_{e}(\mathrm{mg} / \mathrm{g})$ is the amount of impurity adsorbed per unit mass of material (sorbent), $C_{e}(\mathrm{mg} / \mathrm{l})$ the final concentration of unadsorbed impurity in solution, $q_{m}(\mathrm{mg} / \mathrm{g})$ the monolayer adsorption capacity and $\mathrm{K}_{\mathrm{L}}(\mathrm{l} / \mathrm{mg})$ the Langmuir equilibrium constant. $\mathrm{q}_{\mathrm{e}}$ is expressed as,
$q_{e}=\frac{\left(C_{i}-C_{f}\right) V}{\text { mass }}$

where $C_{i}$ is the initial concentration, $C_{f}$ the final concentration, and $V$ the volume of impurity solution. The volume of impurity and mass of material remains constant for a given set of analyses. A plot of $C_{e} / q_{e}$ against $C_{e}$ gives the Langmuir isotherm. The Langmuir constants are obtained from the slope $\left(\mathrm{q}_{\mathrm{m}}\right)$ and intercept $\left(\mathrm{K}_{\mathrm{L}}\right)$, and the model's characteristics can be expressed in terms of $\mathrm{R}_{\mathrm{L}}$ a dimensionless constant for the separation factor to depict whether the adsorption is favourable or unfavourable-Eq. (8):

$R_{L}=\frac{1}{1+K_{L} C_{i}}$

where $C_{i}$ is initial concentration. The characteristics of $R_{L}$ for favourable adsorption are $0<R_{L}<1$, for unfavourable adsorption $R_{L}>1$, for linear adsorption $R_{L}=1$, and for irreversible adsorption $R_{L}=0$.

\subsubsection{Freundlich adsorption isotherm}

This isotherm is based on the assumption that the adsorbent has a heterogeneous surface with numerous adsorption sites. The linear form of the Freundlich equation is given below,

$q_{e}=K_{f} C_{e}^{\frac{1}{n}}$

where $\mathrm{n}$ is the Freundlich exponent and $\mathrm{K}_{\mathrm{f}}$ the Freundlich constant, which measures heterogeneity; the higher the $K_{f}$ the more heterogeneous the adsorbent. To determine the Freundlich isotherm, a plot of $\log \mathrm{q}_{e}$ against $\log C_{e}$ gives a slope equal to $1 / n$ and an intercept at log $K_{f}$. The slope $1 / n$ represents a collective value of the relative magnitude of adsorption intensity for a certain sorption process.

$\log q_{e}=\log K_{f}+\frac{1}{n} \log C_{e}$

To determine the applicability and suitability of a particular isotherm model (Langmuir or Freundlich) to the experimental data the regression coefficient $\left(R^{2}\right)$ is calculated from the plot of $\log \mathrm{q}_{\mathrm{e}}$ versus $\log \mathrm{k}_{\mathrm{f}}$.

\subsection{Reusability of smart composite materials [4]}

The reusability was determined by measuring the number of times an optimised weight of material could be used to lower impurity concentration from a fresh solution to $50 \%$ 
of its initial value, each time. To do this the best effective concentration of material was added to a $10 \mathrm{ml}$ aliquot of known impurity solution/effluent at the optimised temperature and time. After treatment, the amount of impurity remaining in solution was determined. Subsequently a fresh aliquot of impurity was treated using the same material from the previous stage and the proportional removal was calculated. The stages were repeated until the proportional removal of impurity reached $50 \%$ of actual. In each stage to evaluate reusability, the proportional desorption was also evaluated to gauge the materials uptake and thus determine their reusability. After adsorption the material was re-dissolved in distilled water and the impurity leached by desorption was calculated using Eq. (11).

$\%$ desorption $=\frac{\text { Conc of impurity leached }}{\text { Conc of impurity adsorbed }} \times 100$

\section{Results and discussion}

\subsection{Determination of LCST}

The LCST values obtained from the cloud point measurements were confirmed using a differential scanning calorimeter (DSC). Figure 2a shows the thermogram for GP-09 and Table 3 summarises the DSC events for other materials. The LCST of NIPAAM, DEA and NVCL homopolymer is $32^{\circ} \mathrm{C}$ and that observed for the smart composite materials (GP-09, 10 and 11) are in the range of $34-38^{\circ} \mathrm{C}$. Also, for DMAEMA homopolymer the LCST value is $49^{\circ} \mathrm{C}$ and for smart composite (GP-12) is found to be $52^{\circ} \mathrm{C}$. This shift of LCST values is due to the increase/decrease in the hydrophilic properties of the material owing to addition or change of functional groups. A similar shift in the LCST values was evident in our previous paper and was confirmed using DSC [4].

\subsection{FT-IR analysis}

As shown in Fig. $2 b$ the FT-IR spectrum of GP-09 shows characteristic peak of amide at $1643 \mathrm{~cm}^{-1}$ present in the NIPAAM unit of the composite. The signal at $3300 \mathrm{~cm}^{-1}$ is due to the hydroxyl groups present in the pullulan backbone. The $\mathrm{N}-\mathrm{H}$ bend at $1457 \mathrm{~cm}^{-1}$ and $\mathrm{C}-\mathrm{O}$ ether stretch at $1021 \mathrm{~cm}^{-1}$ correspond to signals from NIPAAM and pullulan. Similar characteristics are observed for the other smart composites thus confirming that the graft was successful.

\section{$4.3^{1} \mathrm{H}-\mathrm{NMR}$}

The smart composite material GP-09 was further characterized by ${ }^{1} \mathrm{H}$-NMR spectroscopy (Fig. 3). The peak at $\delta 7.73 \mathrm{ppm}$ can be attributed to the $-\mathrm{N} \underline{\mathrm{H}}$ resonance of the amide group from the NIPAAM unit. The peak at $\delta$ $2.02 \mathrm{ppm}$ is due to the methine proton of the isopropyl group [- $\left.\mathrm{CH}\left(\mathrm{CH}_{3}\right)_{2}\right]$ and at $\delta 1.59 \mathrm{ppm}$ for the methylene protons $\left[-\mathrm{CH}_{2}-\mathrm{CH}-\mathrm{CO}-\mathrm{NHCH}\left(\mathrm{CH}_{3}\right)_{2}\right]$ of the NIPAAM unit. The peaks labelled as $\mathrm{C} 2, \mathrm{C} 3, \mathrm{C} 4$ and $\mathrm{C} 5$ as seen from $\delta 3.36$ to $4.04 \mathrm{ppm}$ are for the hydrogen from the pullulan backbone. The distinct peak at $\delta 1.16 \mathrm{ppm}$ is due to the methyl groups $\left[-\mathrm{CH}\left(\mathrm{CH}_{3}\right)_{2}\right]$ and resonance at $\delta 3.92 \mathrm{ppm}$ represents the methine [- $\mathrm{C}-\mathrm{H}-\mathrm{CO}-\mathrm{NH}-]$ of NIPAAM moiety. The resonances at $\delta 5.40$ and $5.41 \mathrm{ppm}$ are due to the hydrogens from the 1,4 linkage of the pullulan unit. Thus, the spectrum confirms the structure of GP-09.

\subsection{Molecular weight determination}

The approximate molecular weight obtained for smart composite materials are given in Table 3 . The grafting ratio (GR) is dependent on the amount of temperature responsive polymer grafted onto the pullulan backbone. It is observed that the graft ratio is nearly same for all the materials which can be attributed to constant weight of pullulan and also similar molecular weights of temperature responsive polymers as obtained from the extraction method. Thus, suggesting analogous grafting for all the materials and equivalent addition of the homopolymer onto pullulan backbone.

\subsection{Surface area and porosity}

The surface area and porosity of GP-09 were calculated from the adsorption isotherm obtained by measuring the amount of gas adsorbed across a wide range of relative pressures from 10 to $70 \mathrm{kPa}$ at constant temperature (liquid nitrogen $77 \mathrm{~K}$ ) in triplicate. The amount of gas adsorbed is correlated to the total surface area of the particles including pores in the surface. The BET specific surface of GP-09 was determined as $0.128 \mathrm{~m}^{2} / \mathrm{g}$, while the BJH plot shows the pore specific surface as $0.122 \mathrm{~m}^{2} / \mathrm{g}$. Although the smart composite materials have a relatively small surface area compared to conventional adsorbents, they still exhibit effective adsorbent properties due to high specificity at LCST i.e. when the positions of the hydrophilic and hydrophobic groups are reversed in their regular structural scaffold. The presence of hydrophobic groups on the surface of the smart composite materials (adsorbate) results in low/no hydrogen bonding interaction with water molecules, thereby increasing the 


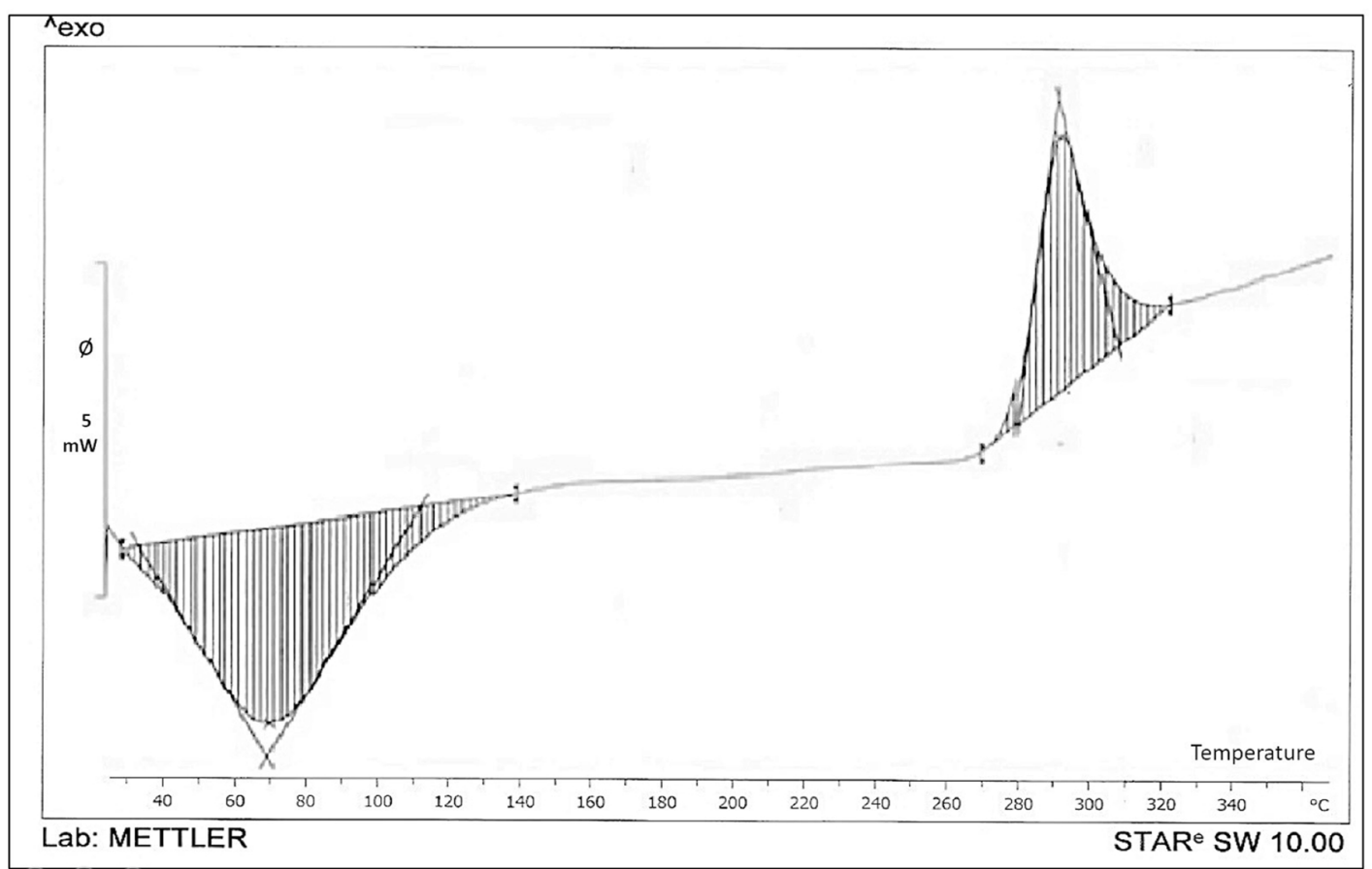

(a) DSC thermogram of GP-09

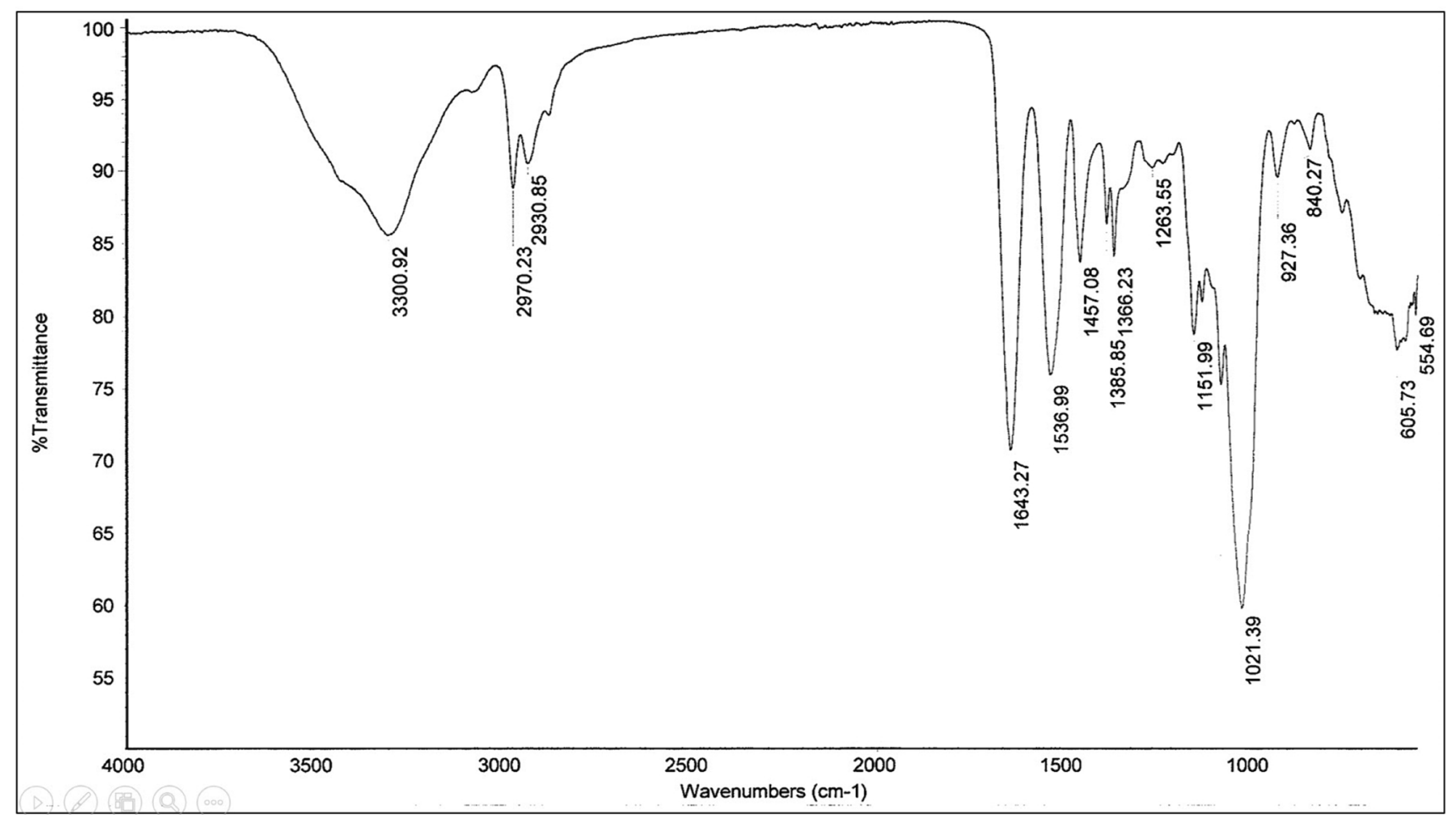

(b) FT-IR spectrum of GP-09

Fig. 2 a DSC thermogram of GP-09 b FT-IR spectrum of GP-09 
Table 3 Endothermic events and Molecular weights of the smart composite materials

\begin{tabular}{llrrr}
\hline Material & \multicolumn{2}{l}{ Endothermic events $\left({ }^{\circ} \mathrm{C}\right)$} & $\begin{array}{l}\text { Molecular } \\
\text { weight (D) }\end{array}$ \\
\cline { 2 - 4 } & Onset (LCST) & Peak & Endset & \\
\hline GP-09 & 35.23 & 75.94 & 122.28 & 279,500 \\
GP-10 & 34.97 & 41.02 & 62.59 & 259,740 \\
GP-11 & 50.38 & 70.02 & 114.92 & 270,000 \\
GP-12 & 35.56 & 63.94 & 94.62 & 275,600 \\
\hline
\end{tabular}

hydrophobic surface, and the adsorption power. From the $\mathrm{BJH}$ plot the pore volume and pore width are $0.005 \mathrm{~cm}^{3} / \mathrm{g}$ and $3.70 \mathrm{~nm}$, respectively. The pore widths of the smart composite materials are in the range 2 to $10 \mathrm{~nm}$, as observed for adsorbents like zeolites. Thus it can be classified as mesoporous according to the IUPAC classification [12]. The pore width for GP-09 suggests that the area available for adsorption is the same as for standard adsorbents.

\subsection{Optimization and evaluation of adsorption potential}

\subsubsection{Optimization of adsorption potential}

The smart composite materials extract known concentrations of impurities effectively which is evident by the decrease in the absorbance with increase in the contact time. The treatment was continued until the solution reached equilibrium. It is also observed that with increase in the polymer concentration, equilibrium is attained quicker (Fig. 4). The optimum concentrations and contact times are above the LCST of the materials for a fixed impurity concentration (chlorophenol $50 \mathrm{ppm}$ ) as shown in Table 4.
Fig. $3{ }^{1} \mathrm{H}$-NMR spectrum of GP-09 a Full spectrum b Spectrum from 1.0 to $4.0 \mathrm{ppm}$

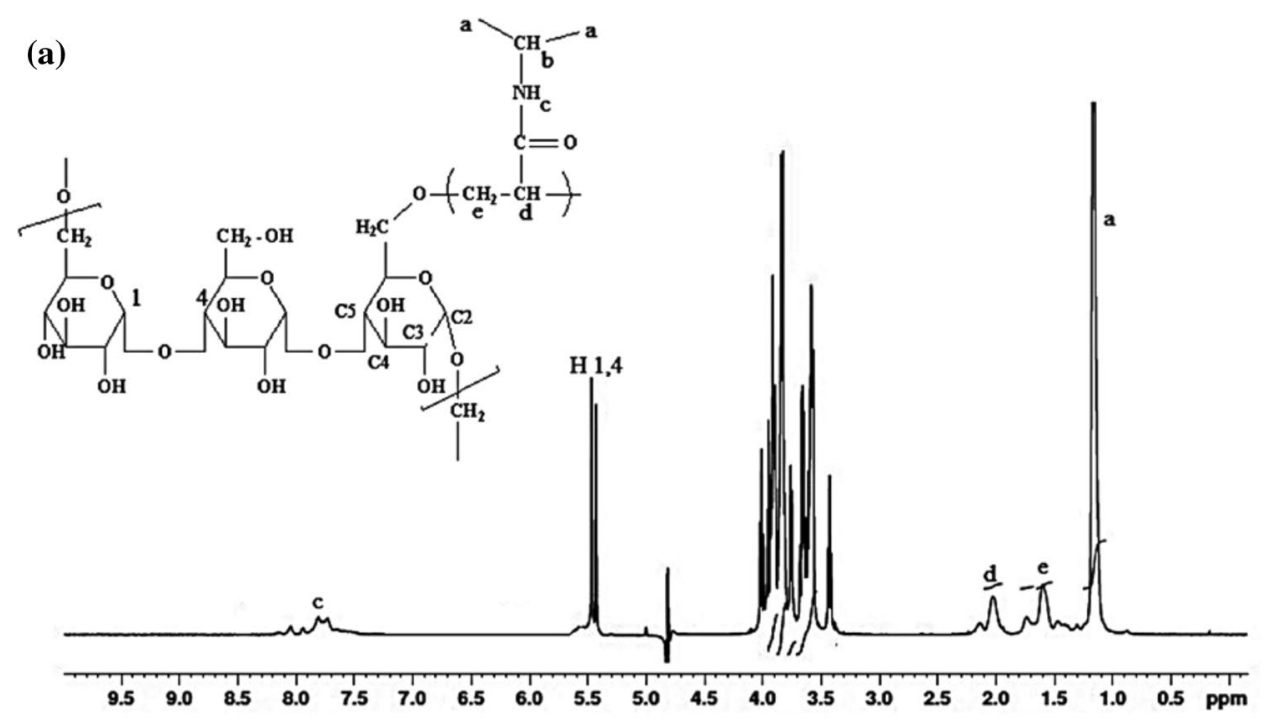

(b)

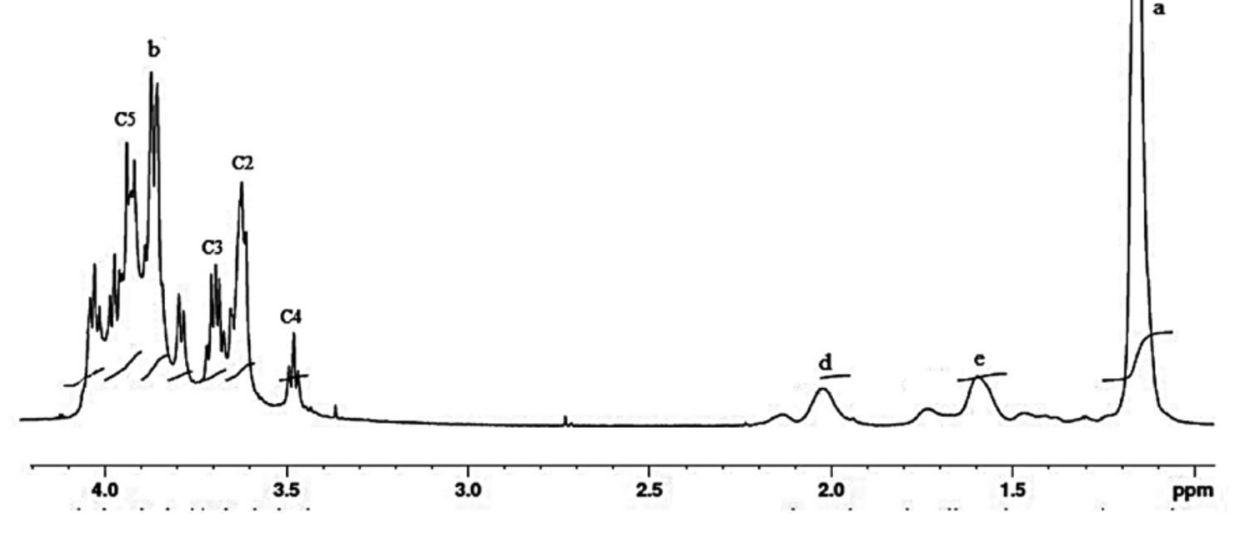


(a)

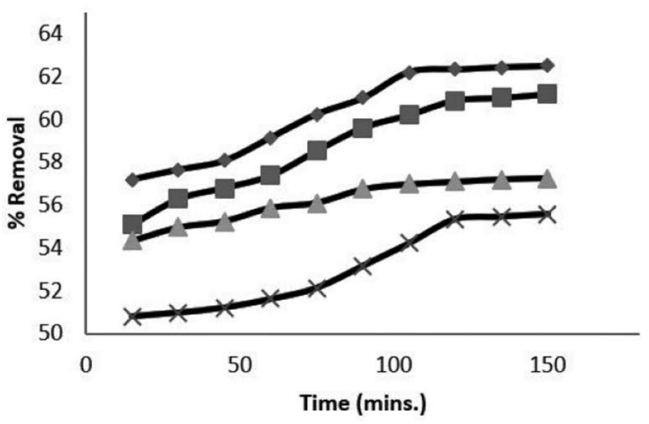

(b)

$0.2 \%$ solution

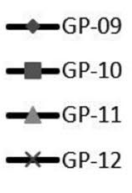

GP-09

- 든-10

$\rightarrow$ GP-11

$\leftarrow$ GP-12

(c)

$0.4 \%$ solution

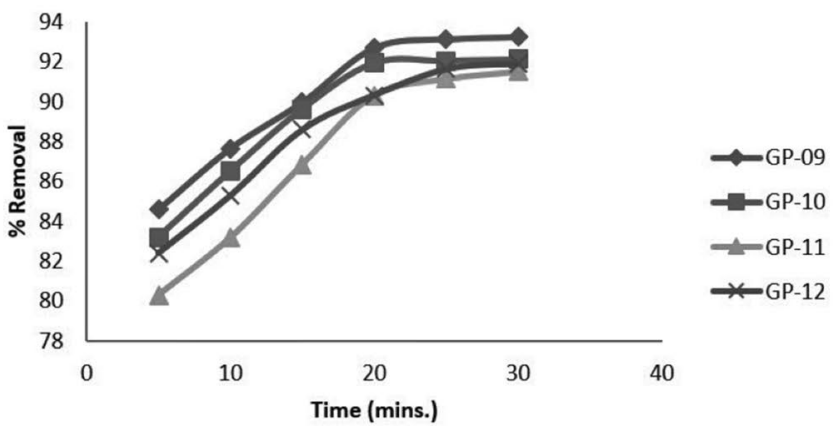

Fig. 4 Optimization of equilibrium contact time for maximum adsorption for various smart composite materials at concentration $\mathbf{a} 0.1 \% \mathbf{b}$ $0.2 \%$ c $0.4 \%$ (All measurements made at $5^{\circ} \mathrm{C}$ above the LCST of the materials) [values are mean \pm S.D.]

Table 4 Optimised conditions and maximum chlorophenol removal efficiency by various smart composite materials $(0.4 \% \mathrm{w} / \mathrm{v})$

\begin{tabular}{|c|c|c|c|}
\hline \multirow{2}{*}{$\begin{array}{l}\text { Smart composite material } \\
\text { (GP) }(0.4 \% \mathrm{w} / \mathrm{v})\end{array}$} & \multicolumn{3}{|l|}{ Effect of contact time } \\
\hline & $\begin{array}{l}\text { Proportional removal efficiency } \\
\text { (chlorophenol } 50 \text { ppm) \% }\end{array}$ & $\begin{array}{l}\text { Equilibrium contact } \\
\text { time (min) }\end{array}$ & $\begin{array}{l}\text { Tempera- } \\
\text { ture }\left({ }^{\circ} \mathrm{C}\right)\end{array}$ \\
\hline GP-09 & 93.25 & 15 & 40 \\
\hline GP-10 & 92.13 & 20 & 40 \\
\hline GP-11 & 91.51 & 25 & 55 \\
\hline GP-12 & 91.88 & 20 & 40 \\
\hline
\end{tabular}

\subsubsection{Evaluation of adsorption potential under optimised conditions}

The smart composite materials at concentration of $0.4 \% \mathrm{w} / \mathrm{v}$ under optimised contact times and temperatures were evaluated for extraction of a range of impurities and the results are presented in Tables 5 and 6 (metal ions evaluated by ICP-OES). All the smart composite materials exhibited similar extraction efficiencies for the various impurities. However, GP-09 displayed the highest impurity removal in the shortest contact time under respective optimised temperature. This adsorption and extraction of impurities including organic, inorganic dyes, agrochemical, metal ions and pharmaceuticals by the smart composite materials can be attributed to the existence of a combined action from pullulan and the temperature responsive polymer. Since each impurity was studied in isolation, it was interesting to evaluate preferential adsorption if any for a set of impurities (chlorophenol and phthalic anhydride) present together in a single solution. The results by HPLC confirmed that there is no preferential adsorption for the given set of impurities and the materials adsorb these impurities irrespective of their structural features. Also these materials are able to extract different metal ions when present together, which is an attractive feature of the materials. Moreover, the markedly reduced value of COD for the industrial effluent samples when 

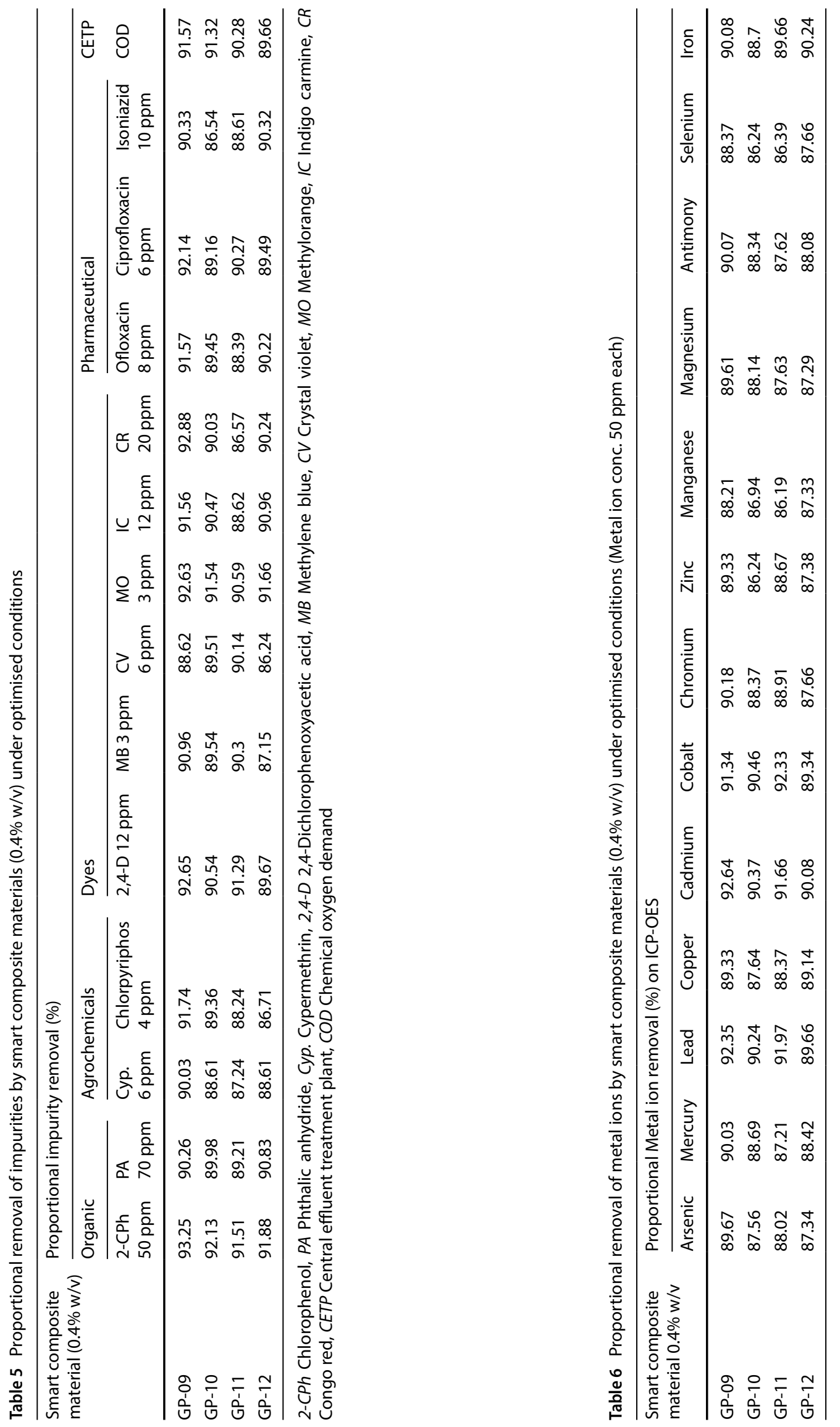
Fig. 5 Adsorption isotherm model of chlorophenol on GP-09 a Langmuir and b Freundlich

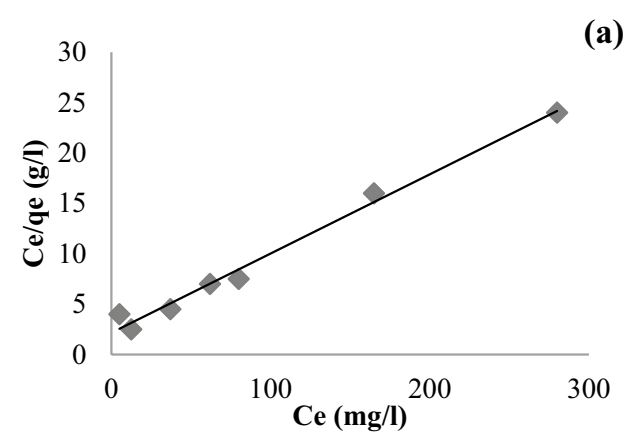

(a)

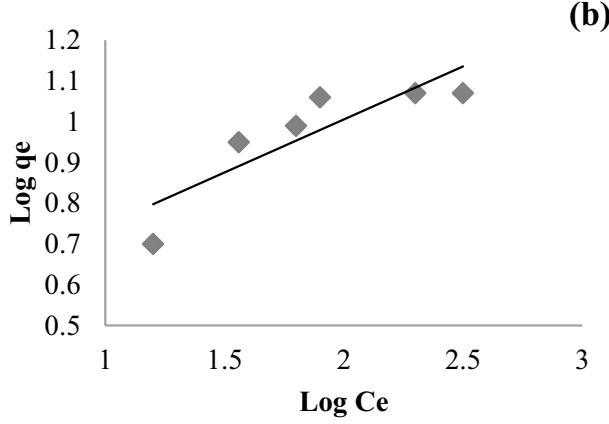

Table 7 Constants for the two isotherm models

\begin{tabular}{|c|c|c|c|c|c|c|c|}
\hline \multirow[t]{2}{*}{ Smart composite material } & \multicolumn{4}{|c|}{ Langmuir constants } & \multicolumn{3}{|c|}{ Freundlich constants } \\
\hline & $\mathrm{q}_{\mathrm{m}}(\mathrm{mg} / \mathrm{g})$ & $\mathrm{K}_{\mathrm{L}}(\mathrm{L} / \mathrm{mg})$ & $\mathrm{R}^{2}$ & $\mathrm{R}_{\mathrm{L}}$ & $\mathrm{K}_{\mathrm{F}}$ & $1 / n$ & $\mathrm{R}^{2}$ \\
\hline GP-09 & 11.6 & 0.049 & 0.98 & 0.060 & 3.81 & 0.2139 & 0.76 \\
\hline
\end{tabular}

treated with these materials indicated the simultaneous removal of impurities from industrial water.

Synthetic polymers like polyacrylamide as a flocculent have been extensively reported for COD reduction [13], but its use is limited due to environmental consequences and health hazards. Also natural polymers like chitosan, tannins, and cellulose derivatives being biodegradable and extremely good in COD reduction face challenges due to their shorter shelf life and stability [14]. Hence in the current study these polymers when combined together not only reduce the COD in a similar way as observed for their individual counterparts but also overcome the shortcomings of both the aforementioned polymers.

As discussed in the previous section, these composite materials have the potential to remove more than $90 \%$ of contaminants from wastewater at the optimum concentration of $0.4 \% \mathrm{w} / \mathrm{v}$ at LCST. These materials have been synthesized in a single step from individual polymers (natural and synthetic) in an economical fashion and thus can easily be mass produced. Therefore, the ease and high reproducibility of the synthetic process commends itself to easy scaleup in amounts required for commercial purposes. Also, the industrial applicability can be extended by converting these materials as nanoparticles/microspheres/nanofibers. Such fabrications will ensure that smaller quantities of the material can be used (economic viability) for wastewater treatment without compromising on the efficiency as reported by Ammar et al. [15]..

\subsection{Adsorption isotherm analysis}

The smart composite material GP-09 was studied using the Langmuir and Freundlich models. The models terms are calculated and $\mathrm{R}^{2}$ values are obtained for both the isotherms (Fig. 5). Table 7 shows the constants for the two isotherm

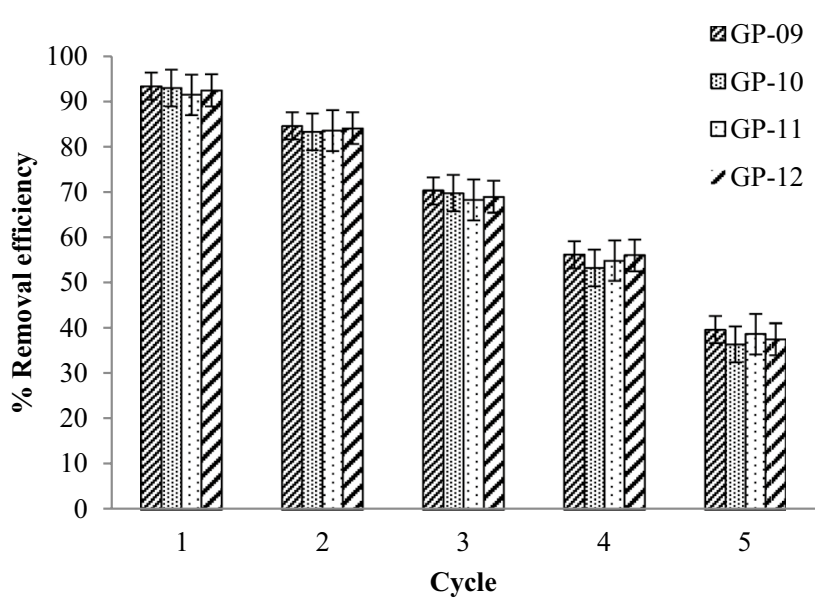

Fig. 6 Reusability of graft smart materials

models and it is clear that the Langmuir model provides a better fit than the Freundlich model, indicating monolayer adsorption on the surface of smart composite materials. Literature studies following similar Langmuir adsorption for removal of arsenic metal ions from water using a polyacrylamide hybrid has been reported by Sandip Mandal et al. [16]. The materials reported also show monolayer adsorption as seen in case of composite materials.

\subsection{Reusability of smart composite materials}

This study was carried out at the optimised time frame and concentration for maximum efficiency. As shown in Fig. 6, GP-09 has slightly better removal efficiency of the four smart composite materials tested when used repeatedly with fresh stock of impurity. All the materials lose more than $50 \%$ of their efficiency after 4 cycles of reuse. The reusability and 
efficiency of these materials is found to be almost similar to the polymers reported in our earlier communications $[4,5]$.

\section{Conclusion}

The end product/technology of the current work delivers novel smart composite materials for simultaneous removal of contaminants ( $90 \%$ and above) from effluent water which can be further reused for various other processes in the industry. Thus, the first and foremost outcome is a system that enables and encourages optimal water use. A significant reduction in the level of Chemical Oxygen Demand (COD) was also observed for effluent water pooled from chemical, textile, agrochemical and pharmaceutical industries. The smart composite materials have also been tested for their reusability and have proven to be useful for at least 4 cycles. Their ability to take up all impurities concurrently, coupled with the ease of handling marks them as an advanced innovation that can act as an improvement to the current technologies used in industries for reuse in wastewater treatment systems. The materials also project as proof of concept for an application that ensures complete water conservation and wastewater recovery from the industrial effluent.

Acknowledgements The authors would like to thank (i) University Grants Commission (UGC), India [File No. 43/489 (SR)] for providing financial assistance for this Project. (ii) SLN pharmachem and Nagase India Pvt. Ltd. for the gift samples of NIPAAM and Pullulan respectively. (iii) Metrohm India Pvt. Ltd for the surface area and porosity determinations. (iv) Dr. Shardul kulkarni and Dr. Nitin Kulkarni, Lab India Pvt. Ltd. for ICP-OES analysis of the samples.

\section{Compliance with ethical standards}

Conflict of interest The authors declare that they have no conflict of interest.

Open Access This article is licensed under a Creative Commons Attribution 4.0 International License, which permits use, sharing, adaptation, distribution and reproduction in any medium or format, as long as you give appropriate credit to the original author(s) and the source, provide a link to the Creative Commons licence, and indicate if changes were made. The images or other third party material in this article are included in the article's Creative Commons licence, unless indicated otherwise in a credit line to the material. If material is not included in the article's Creative Commons licence and your intended use is not permitted by statutory regulation or exceeds the permitted use, you will need to obtain permission directly from the copyright holder. To view a copy of this licence, visit http://creativecommons. org/licenses/by/4.0\%.

\section{References}

1. Du B, Price AE, Scott WC, Kristofco LA, Ramirez AJ, Chambliss CK, Yelderman JC, Brooks BW (2014) Comparison of contaminants of emerging concern removal, discharge, and water quality hazards among centralized and on-site wastewater treatment system effluents receiving common wastewater influent. Sci Total Environ 466:976-984

2. Tong T, Elimelech M (2016) The global rise of zero liquid discharge for wastewater management: drivers, technologies, and future directions. Environ Sci Technol 50(13):6846-6855

3. Gunatilake $S$ (2015) Methods of removing heavy metals from industrial wastewater. Methods 1(1):14

4. Paneysar JS, Barton S, Chandra S, Ambre P, Coutinho E (2016) Novel thermoresponsive assemblies of co-grafted natural and synthetic polymers for water purification. Water Sci Technol 75(5):1084-1097

5. Js Paneysar, Sawant S, Ip MH, Sk Bhullar, Barton S, Ambre P, Coutinho E (2019) Nanofibers for textile waste water management. Water Pract Technol 14(2):297-310

6. Aguilar MR, San Román J (2019) Smart polymers and their applications. Woodhead Publishing, Cambridge

7. Aguilar MR, Elvira C, Gallardo A, Vázquez B, Román J (2007) Smart polymers and their applications as biomaterials. Top Tissue Eng 3(6):1-27

8. Saitoh T, Yoshida Y, Matsudo T, Fujiwara S, Dobashi A, Iwaki K, Suzuki Y, Matsubara C (1999) Concentration of hydrophobic organic compounds by polymer-mediated extraction. Anal Chem 71(20):4506-4512

9. Saber-Samandari S, Gulcan HO, Saber-Samandari S, Gazi M (2014) Efficient removal of anionic and cationic dyes from an aqueous solution using pullulan-graft-polyacrylamide porous hydrogel. Water Air Soil Pollut 225(11):2177

10. Ghimici L, Constantin M (2011) Novel thermosensitive flocculanting agent based on pullulan. J Hazard Mater 192(3):1009-1016

11. Chakraborty S, Purkait M, DasGupta S, De S, Basu J (2003) Nanofiltration of textile plant effluent for color removal and reduction in COD. Sep Purif Technol 31(2):141-151

12. Dąbrowski A (2001) Adsorption-from theory to practice. Adv Colloid Interface Sci 93(1-3):135-224

13. Wong S, Teng T, Ahmad A, Zuhairi A, Najafpour G (2006) Treatment of pulp and paper mill wastewater by polyacrylamide (PAM) in polymer induced flocculation. J Hazard Mater 135(1-3):378-388

14. Tetteh EK, Rathilal S (2019) Application of organic coagulants in water and wastewater treatment. In: Organic polymers. IntechOpen

15. Ammar N, Fahmy A, Kanawy Ibrahim S, Hamzawy EMA, ElKhateeb M (2017) Wollastonite ceramic/CuO nano-composite for cadmium ions removal from waste water. Egypt J Chem 60(5):817-823

16. Mandal S, Sahu MK, Patel RK (2013) Adsorption studies of arsenic (III) removal from water by zirconium polyacrylamide hybrid material (ZrPACM-43). Water Resour Ind 4:51-67

Publisher's Note Springer Nature remains neutral with regard to jurisdictional claims in published maps and institutional affiliations. 